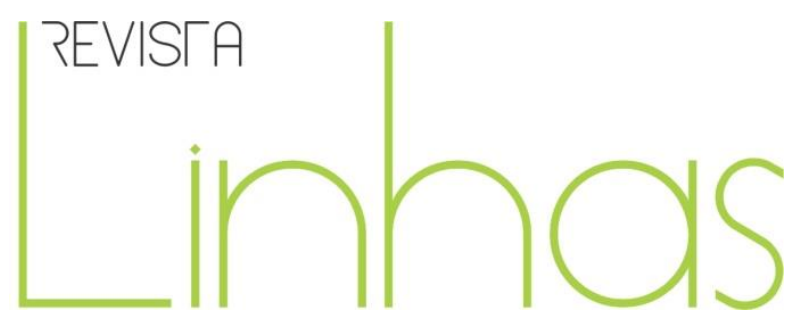

\title{
Problematizando o ensino de frações com um grupo de professores do ensino fundamental
}

\begin{abstract}
Resumo
Os alunos da Educação Básica ainda demonstram dificuldades quando o assunto envolve os números racionais, tanto em relação ao significado quanto às operações. Tais dificuldades podem estar relacionadas à forma de ensino do conteúdo que, muitas vezes, depende do conhecimento que os professores possuem. Nesse sentido, é fundamental investigar o conhecimento docente, visando à diminuição de possíveis problemas de aprendizagem desse conteúdo. Este artigo socializa a análise dos resultados decorrentes de uma investigação de cunho qualitativo, caracterizada como pesquisa de levantamento, em que foi utilizado um questionário para coleta de dados. Salienta-se que o objetivo foi investigar as concepções de um grupo de professores do Ensino Fundamental sobre o ensino de frações com foco nos significados, importância para o currículo escolar e aplicabilidade no cotidiano. Os resultados indicaram que a maioria dos pesquisados relacionava frações apenas com o sentido parte-todo, sendo que poucos tinham conhecimento dos outros significados. Quanto às situações do cotidiano em que as frações são usadas, foram citadas receitas e divisão de alimentos (pizzas, bolos, chocolates). Em relação à importância do conteúdo no currículo, as respostas divergiram, destacando-se que a presença das frações era para entender a operação de divisão. Frente a esses resultados, pode-se inferir que há a necessidade de formação de professores, em particular dos Anos Iniciais, para que estes compreendam os diversos conceitos relacionados às frações, bem como problematizar a relevância desse tema no currículo escolar e as formas de ensinar tais conceitos.
\end{abstract}

Palavras-chave: Frações - Estudo e ensino. Professores - Formação. Matemática (Ensino fundamental).

\author{
Marli Teresinha Quartieri \\ Universidade do Vale do Taquari - \\ Univates - Lajeado/RS - Brasil \\ mtquartieri@univates.br \\ leda Maria Giongo \\ Universidade do Vale do Taquari - \\ Univates - Lajeado/RS - Brasil \\ igiongo@univates.br
}

\section{Márcia Jussara Hepp Rehfeldt}

Universidade do Vale do Taquari Univates - Lajeado/RS - Brasil mrehfeld@univates.br

\section{Para citar este artigo:}

QUARTIERI, Marli Teresinha; GIONGO, leda Maria; REHFELDT, Márcia Jussara Hepp. Problematizando o ensino de frações com um grupo de professores do ensino fundamental. Revista Linhas. Florianópolis, v. 21, n. 45, p. 381-403, jan./abr. 2020. 


\title{
Problematizing the teaching of fractions with a group of primary school teachers
}

\begin{abstract}
Basic Education students still encounter difficulties when dealing with rational numbers, both regarding their meaning and operations. Such difficulties might refer to the manner this content is taught; this, quite often, depends on the knowledge teachers have about it. Therefore, investigation of teachers' knowledge becomes essential in order to reduce potential learning problems with this content. This article shares the analysis of outcomes of a qualitative investigation, more specifically a survey research using a questionnaire to collect data. It is emphasized that the objective was to investigate the conceptions of a group of primary school teachers about the teaching of fractions focusing on meanings, importance for the school curriculum and everyday applicability. The outcomes showed that most of the researched teachers related fractions only with part-whole, and few of them were familiar with other meanings. Concerning the daily situations in which fractions are used, recipes and food divisions (pizzas, cakes, chocolate bars) were mentioned. With regards to the importance of this content in the syllabus, answers differed, but fractions leading to the understanding of the division operation was the most common one. Consequently, the conclusion is the need for further teacher education, particularly those of the Early Years, so that they become aware of the several concepts about fractions, as well as for problematizing this theme in school syllabus and the manners to teach such concepts.
\end{abstract}

Keywords: Fractions - Study and teaching. Teachers Training. Mathematics (Primary School). 
A natureza e o desenvolvimento dos diversos saberes e conhecimentos necessários para o ensino na Escola Básica têm sido o centro da pesquisa tanto em nível nacional como internacional (COSTA, 2010; IMBERNÓN, 2010; RIBEIRO, 2012; TARDIF, 2002). Alguns trabalhos também têm procurado diagnosticar o conhecimento matemático de professores e, em especial, fraquezas e deficiências (LAMON, 2012; MANDARINO, 2006; MOREIRA, DAVID, 2007). Ribeiro (2012), por sua vez, destaca que pesquisadores têm assinalado a necessidade de o foco da pesquisa estar direcionado naquilo que os professores "não sabem" e, dessa forma, potencializar as experiências e os conhecimentos por eles construídos a partir da prática de sala de aula. É nessa perspectiva que a presente investigação se insere.

Quanto ao conteúdo de frações, os processos de ensino e de aprendizagem revelam dificuldades na Educação Matemática, as quais, segundo Costa (2010), ocorrem pela falta de compreensão tanto por parte dos alunos quanto dos professores. Estes demonstram não conhecer os diferentes significados que as frações apresentam nas diversas situações de aprendizagens. Desse modo, Valera (2003) comenta que docentes que possuem limitações conceituais em relação aos números racionais se deparam com obstáculos ao trabalharem com os diversos registros desse conteúdo, especialmente os diferentes significados de frações. Assim, "sem competências fundamentais para lidar com essa representação também não são promovidas situações que estimulem nos alunos o desenvolvimento de um sentido para os números racionais, gerando barreiras para sua compreensão." (VALERA, 2003, p. 3).

Diante desse contexto, o presente artigo socializa resultados decorrentes de uma das ações da pesquisa intitulada "Estratégias metodológicas visando à inovação e reorganização curricular no campo da Educação Matemática no Ensino Fundamental”. A investigação fez parte do Programa Observatório da Educação, desenvolvido em uma Instituição de Ensino Superior, no interior do Estado do Rio Grande do Sul, no período de 2013 a 2017, contando com apoio da CAPES (Coordenação de Aperfeiçoamento de Pessoal de Nível Superior). 
Os componentes do grupo foram quatro professores da Instituição (três diplomados em Licenciatura em Matemática e um em Pedagogia); seis mestrandos do Mestrado Profissional em Ensino de Ciências Exatas; seis bolsistas de iniciação científica e seis professoras de Matemática do Ensino Fundamental, representantes de seis escolas parceiras participantes do referido Observatório. Semanalmente, o grupo se reunia para discutir e problematizar um ensino diferenciado, visando três tendências da Matemática: Investigação Matemática; Modelagem Matemática e Etnomatemática. O objetivo foi problematizar e propor estratégias metodológicas com vistas à inovação e reorganização curricular na disciplina Matemática em seis escolas públicas de Educação Básica do Vale do Taquari, RS, que possuíam considerável distância entre o IDEB relativo a $4^{\mathrm{a}}$ série $/ 5^{\circ}$ ano e $8^{\mathrm{a}}$ série $/ 9^{\circ}$ ano.

Nas reuniões, os professores das escolas parceiras comentavam as dificuldades, em particular dos docentes dos Anos Iniciais, quanto ao conteúdo de frações. Em vista disso, os pesquisadores decidiram lhes proporcionar formação continuada, na forma de oficinas, nas próprias escolas, sobre o conteúdo de frações, não somente para os que ministravam aulas nos Anos Iniciais do Ensino Fundamental, mas também para os de Matemática dos Anos Finais.

O intuito deste artigo é socializar a análise dos resultados decorrentes de um questionário aplicado a setenta professores dos Anos Iniciais e de Matemática dos Anos Finais das seis escolas parceiras no início da formação continuada. Salienta-se que o objetivo foi investigar as concepções de um grupo de professores do Ensino Fundamental sobre o ensino de frações com foco nos significados, importância para o currículo escolar e aplicabilidade no cotidiano. Assim, a investigação teve cunho qualitativo, caracterizando-se como pesquisa de levantamento, em que foi utilizado um questionário para coleta de dados.

\section{Ensino de frações e seus significados}

Os conhecimentos acerca dos números, desenvolvidos na base do processo de escolarização, representam importantes alicerces sobre os quais se desenvolverão, posteriormente, outros conceitos matemáticos. Behr et al (1983, p. 91) já afirmavam que 
"os conceitos relacionados aos números racionais estão entre as ideias mais complexas e importantes que as crianças encontram ao longo dos primeiros anos de escolarização." Campos (2009), por sua vez, comenta que alguns pesquisadores têm problematizado que a construção dos números racionais desperta dificuldades em todos os níveis de escolarização dos alunos. Nesse mesmo sentido, Canova (2006) e A. Silva (2007) destacam que alguns discentes egressos da Educação Básica têm pouco ou nenhum domínio de noções básicas relativas às frações.

Nessa mesma perspectiva, Valera (2003, p. 12) relata que o ensino dos números racionais se tornou objeto de críticas porque sua abordagem desperta pouco interesse no aluno, "em parte devido ao insuficiente aproveitamento prático dos conteúdos e também pela forma como o programa vem sendo realizado, cuja aplicabilidade do aprendizado não encontra caminho na realidade do aluno". Aliado a essa ideia, Lopes (2008) alude que muitos professores e autores de materiais didáticos desconhecem a história do conceito de frações, bem como suas componentes epistemológica e cognitiva. O autor ressalta que o ensino de frações está ultrapassado; logo, há a necessidade da utilização de metodologias diferenciadas. Em efeito,

O ensino de frações tem sido praticado como se nossos alunos vivessem no final do século XIX, um ensino marcado pelo mecanicismo, pelo exagero na prescrição de regras e macetes, aplicações inúteis, conceitos obsoletos, "carroções", cálculo pelo cálculo. Esta fixação pelo adestramento empobrece as aulas de matemática, toma o lugar de atividades instigantes e com potencial para introduzir e aprofundar ideias fortes da matemática. (LOPES, 2008, p. 20-21)

Em conformidade com as ideias de Lopes, M. Silva (1997, p. 47) explicita que essa forma de ensino acaba "levando a um desenvolvimento precário da linguagem e do reconhecimento de frações, a partir de modelos estáticos que não permitem a aquisição plena desse conhecimento." Ademais, o autor comenta que, no dia a dia, poucas são as frações usadas, citando terço, metade ou quarta parte como aquelas usualmente empregadas em receitas ou repartições. Em consonância com isso, corrobora-se a ideia de Lopes (2008): a constante utilização das frações se tornará cada vez mais escassa. As formas analógicas abrem espaços para as digitais. Esse autor ainda salienta que há necessidade de se entender que a notação decimal está cada vez mais presente no 
cotidiano. Entretanto, ele pontua que "Isto não quer dizer que as frações devam ser abolidas, temos que reconhecer sua importância em contextos não utilitários, que atendem a outros significados e objetivos." (LOPES, 2008, p. 5).

Reconhecendo as dificuldades relativas ao aprendizado desse conjunto numérico, Moreira e David afirmam que

O professor da escola básica tem que trabalhar com os significados concretos das frações e outros subconstructos para que o aluno alcance, eventualmente, a ideia abstrata de número racional, mas esse processo de construção da abstração não como resultado apenas da demonstração da possibilidade de se exibir formalmente um conjunto com as características essenciais (e já concebidas) dos racionais. Ao contrário, este novo conjunto numérico ampliado, assim como as relações entre seus elementos (os novos números), as novas formas de representação, a nova ordem, as novas operações e suas novas propriedades, são conhecimentos novos a serem processados e, eventualmente, assimilados. (MOREIRA; DAVID, 2007, p. 61)

Entretanto, para que o docente proporcione esse ensino, há necessidade de ele conhecer e compreender os conceitos relacionados às frações. Lamon (2007, p. 633) argumenta que, por vezes, "os professores lutam com as mesmas dificuldades e apresentam os mesmos mal-entendidos dos alunos". Esse é um ponto crucial, dado que o conhecimento do professor acaba comprometendo a aprendizagem dos seus alunos. Portanto, sua formação deveria ser, efetivamente, fundamentada na compreensão do conhecimento matemático e didático, tendo por base o saber das formas de aprendizagem dos discentes. Para Nunes e Bryant (1997), o ensino e a aprendizagem das frações são um processo complexo para os alunos, e as dificuldades podem surgir quando eles transferem as propriedades do conjunto dos números naturais para as frações, não compreendendo as características particulares de cada conjunto numérico. Em efeito,

Com as frações, as aparências enganam. Às vezes, as crianças parecem ter uma compreensão completa delas e ainda não a têm. Elas usam os termos corretos, falam sobre frações coerentemente, resolvem alguns problemas, mas diversos aspectos cruciais das frações ainda lhes escapam. De fato, as aparências podem ser tão enganosas que é possível que alguns alunos passem pela escola sem superar dificuldades relativas às frações sem que ninguém perceba. (NUNES; BRYANT, 1997, p. 191) 
Nesse sentido, Justulin e Pirola (2008) comprovaram que os professores dos Anos Iniciais, que são responsáveis pela formação inicial do aluno, possuem pouca formação em termos de conteúdos matemáticos, em particular sobre o tema frações. Muitos deles acabam ensinando esse conteúdo de forma fragmentada e mecânica, pois foi a forma como aprenderam quando estudantes. Conforme Nunes e Bryant (1997), muitos discentes "passam pela escola sem superar as dificuldades" referentes a esse tema, motivo pelo qual permanecem alguns questionamentos: que concepções os professores dos Anos Iniciais têm sobre frações? Como ensinam esse conteúdo? Será que conhecem os diferentes significados relacionados aos números fracionários?

Para Nunes e Bryant (1997), as frações apresentam cinco significados que deveriam ser explorados no decorrer das aulas: parte-todo, quociente, número, operador multiplicativo, medida. O primeiro, de acordo com os referidos autores, é o mais explorado pelos professores nas aulas. A ideia presente nesse significado é a partição de um todo em $n$ partes iguais, representado por $\frac{1}{n}$. Assim, a fração indica a relação que existe entre um número e o total de partes, sendo que o denominador indica o número de partes iguais em que o inteiro foi dividido; e o numerador, o número de partes escolhidas, podendo o todo ser contínuo (uma folha de papel) ou discreto (bolas de gude). Um exemplo: dividir uma pizza em oito partes iguais.

A fração com significado de número envolve a ideia da representação na reta numérica ou ainda na notação decimal do número fracionário. Exemplo: represente o número $\frac{3}{4}$ na reta numérica.

A fração com o significado de medida ocorre quando ela se refere a quantidades, que são medidas pela relação entre duas variáveis. É aquela em que a fração é usada como um índice comparativo entre duas quantidades de uma grandeza. Podem ser exemplos para esse significado situações que envolvem razão, porcentagem, escalas, probabilidade. Exemplo: a razão entre o número de homens e mulheres em uma reunião é de $\frac{3}{5}$. Nesse caso, a leitura é feita da seguinte maneira "de 3 para 5 ", ou seja, para cada três homens há cinco mulheres na reunião.

A fração como operador multiplicativo, segundo Nunes e Bryant (1997), está associada à ação que se deve imprimir sobre um número transformando o seu valor 
(quantidades discretas) ou, ainda, a ideia de ampliação e redução (quantidades contínuas). Exemplo: Jonas ganhou vinte balas e deu $\frac{2}{5}$ para Maria. Com quantas balas ele ficou? Também pode ser um exemplo a seguinte situação: que número se deve multiplicar por cinco para obter três?

E, por fim, a fração como quociente, de acordo com os autores, está presente em situações associadas à partição, ou seja, a partilha equitativamente distribuída. 0 numerador representa o que foi dividido; e o denominador, o número de pessoas que receberam parte do objeto. Esse significado se baseia na divisão de um número por outro, ou seja, $a: b=\frac{a}{b} \operatorname{com~} \mathrm{b} \ngtr 0$.

Exemplo: dividir dois chocolates igualmente para cinco pessoas. Que fração representa o que cada um irá receber?

Destaca-se que os professores só explorarão tais significados e interpretações das frações se tiverem conhecimentos sobre esses diferentes aspetos do conteúdo, sentindose, assim, seguros para o ensino das diferentes abordagens. Portanto, na formação inicial docente, tanto nos Cursos de Pedagogia como nos de Licenciatura em Matemática, é fundamental que sejam explorados tais conceitos, bem como a forma metodológica de abordar tais significados em sala de aula. Ademais, faz-se necessário problematizar em que nível de escolaridade esses diferentes significados podem ser desenvolvidos.

Caso esses estudos não aconteçam na formação inicial, há necessidade de a formação continuada discutir tais ideias para que o ensino de frações ocorra de forma mais significativa. Essas ideias estão em consonância com Rangel, Giraldo e Maculan Filho (2014, p. 62) quando comentam o conhecimento matemático: "não basta saber, é necessário compreender como esse saber se constitui, qual sua natureza e sua origem, bem como compreender em que sentido e em que medida esse saber é relevante para a sala de aula." 


\section{Percurso metodológico}

Nesta pesquisa, utilizou-se uma abordagem qualitativa, pois esse tipo de investigação possibilita um estudo mais flexível do problema, contribuindo para a sua análise e compreensão. O objetivo foi investigar as concepções de um grupo de professores do Ensino Fundamental sobre o ensino de frações com foco nos significados, importância para o currículo escolar e aplicabilidade no cotidiano.

Além disso, caracterizou-se como uma pesquisa de levantamento em que foi utilizado um questionário para coleta de dados. De acordo com Flick (2013, p. 110), a “maioria das pesquisas de levantamento é baseada em questionário. Estes podem ser respondidos na forma escrita ou oralmente, em uma interrogação presencial, com um pesquisador anotando as respostas." No caso da presente pesquisa, ele foi respondido individualmente na forma escrita.

O referido questionário foi aplicado no início da formação continuada ministrada aos docentes dos Anos Iniciais do Ensino Fundamental e Matemática dos Anos Finais com foco no tema frações. As formações ocorreram em seis escolas (cinco estaduais e uma municipal), parceiras do Programa Observatório da Educação, desenvolvido em uma Instituição de Ensino Superior no interior do Estado do Rio Grande do Sul. Em cada um dos seis educandários, realizaram-se quatro momentos de formação; em quatro deles, houve a participação dos professores dos Anos Iniciais e dos de Matemática dos Anos Finais.

A direção de uma das escolas parceiras solicitou que todos os docentes participassem da formação. Por sua vez, o Secretário da Educação solicitou que a formação envolvesse os professores dos Anos Iniciais e os de Matemática dos Anos Finais da rede municipal. Assim, nos encontros, aproximadamente, estiveram presentes setenta professores. Destaca-se que as direções das escolas, assim como os docentes, assinaram um termo de consentimento livre e esclarecido, possibilitando a divulgação dos resultados de forma anônima.

As questões do questionário foram as seguintes: O que você entende por frações? Qual a importância das frações no currículo? Cite situações do cotidiano em que usamos frações. Salienta-se que essas três perguntas foram respondidas no início da formação 
continuada, sendo cada uma delas apresentada em um cartaz. Para isso, os participantes da oficina receberam três pedaços de papel. Respondidas, as questões foram coladas em seu respectivo cartaz e lidas para o grande grupo. Em seguida, ocorreu um momento de problematização e discussão, o qual foi gravado. Além disso, um bolsista de iniciação científica anotou suas percepções no decorrer da socialização em um diário de campo, o qual também se constituiu em um instrumento de coleta de dados. Este artigo pretende socializar e analisar as respostas e discussões dos participantes das formações para cada uma das três questões do referido instrumento.

A análise das respostas dos setenta docentes seguiu alguns pressupostos da análise de conteúdo de Bardin (2016). Assim, foram

[...] destacadas ideias, enunciados e proposições do texto que pudessem ter significado isolado, ou seja, foram determinados os 'núcleos de sentido' que compõem a comunicação e cuja presença, ou frequência de aparição pode significar alguma coisa para o objetivo escolhido. (BARDIN, 2016, p. 105)

Procurou-se, no decorrer da análise das três questões, usar as três fases propostas por Bardin (2016): a) pré-análise; b) exploração das respostas ao questionário; c) tratamento dos resultados e interpretação. De acordo com o referido autor, na préanálise, é feita a leitura e a organização dos dados, realizando uma sistematização inicial das ideias semelhantes. Por sua vez, a fase da exploração das respostas "consiste essencialmente em operações de codificação, decomposição ou enumeração." (BARDIN, 2016, p. 131). Por fim, na etapa do tratamento e da interpretação dos resultados, "o analista, tendo à sua disposição resultados significativos e fiéis, pode então propor inferências ou deduções e adiantar interpretações a propósito dos objetivos previstos, ou que digam respeito a outras descobertas inesperadas." (BARDIN, 2016, p. 101).

Salienta-se que as respostas em cada uma das três questões foram agrupadas de acordo com suas semelhanças, objetivando interpretações imbricadas com o referencial teórico e com o intuito de responder aos objetivos da pesquisa. Também é importante comentar que outros grupos de respostas poderiam ser formados, pois a interpretação dos resultados depende dos critérios usados pelos pesquisadores, das leituras e releituras efetivadas sobre o material emergente dos instrumentos de coleta de dados. 


\section{Discussão e análise dos dados emergentes}

Nesta seção, apresenta-se a análise das respostas de cada uma das três questões imbricadas com ideias de alguns autores que estudam e investigam o tema frações.

a) O que você entende por frações?

No Quadro 1 apresentam-se as respostas dadas, pelos setenta professores, a esta questão com o respectivo percentual de respondentes.

Quadro 1 - Resposta à pergunta "O que você entende por frações?”

\begin{tabular}{|l|c|}
\hline \multicolumn{1}{|c|}{ Respostas identificadas } & Percentual (\%) \\
\hline Fração é divisão de um todo em partes & 49 \\
\hline Fração é a divisão de um todo em partes exatamente iguais & 17 \\
\hline Fração é uma divisão & 12 \\
\hline Fração é proporção & 02 \\
\hline Não responderam ou colocaram que desconheciam o conceito de frações & 20 \\
\hline
\end{tabular}

Fonte: Produção dos autores, 2018.

Verifica-se, portanto, no Quadro 1, que 66\% dos participantes relacionaram a fração com a divisão de um todo. Para esse grupo de investigados, tal conceito está fortemente relacionado ao significado de parte-todo (NUNES; BRYANT, 1997). De acordo com Magina e Campos (2008), talvez, o fato se deva à priorização, no ensino de frações no Brasil, do uso de concepções de situações parte-todo. Segundo eles, esse tipo de situação permite que sejam "explorados aspectos perceptuais em detrimento das relações lógico matemáticas." (MAGINA; CAMPOS, 2008, p. 26). Os nomeados autores acrescentam que, em situações como essas, em que o docente representa uma barra de chocolate dividida em três partes iguais e solicita ao aluno que identifique a fração correspondente a cada parte da barra, "o discente apenas necessita olhar para figura e resolver a questão sem efetuar relações lógico-matemáticas mais complexas." (MAGINA; CAMPOS, 2008, p. 26). Já para Valera (2003), a fração tem sido interpretada apenas como partes de um todo porque muitos professores utilizam, como material de apoio, durante as aulas de frações, o livro didático, que, por sua vez, também se restringe, muitas vezes, ao uso de apenas situações relacionadas a essa concepção. 
Ao analisar as respostas dos professores, é importante refletir sobre a "divisão de um todo em partes" de 40\% dos respondentes, pois nela não está explícito que são partes iguais de um todo. Entretanto, nas discussões que ocorreram na socialização, percebeuse que a ideia dos participantes foi de partes iguais de um todo, comprovando que o ensino de frações está relacionado com partes iguais. Diante disso, problematizou-se a viabilidade de dividir um bolo (um chocolate ou uma pizza) em partes iguais. Os docentes foram unânimes em afirmar que não era possível; entretanto, declararam que usavam tais situações para ensinar frações. Mas, se é inconcebível dividir em partes exatamente iguais esses alimentos, por que são usados no ensino de frações? Será que isso denota a incompreensão do conceito de frações? Como relacioná-las ao cotidiano do aluno?

Nesse sentido, cabe indagar: por que a maioria das respostas envolveu o significado parte-todo, e a minoria, os demais? E outros, que não apareceram? Ademais, somente professores de matemática aludiram à fração como divisão e comparação, fato também merecedor de questionamentos: por que outros não foram mencionados? Se os próprios docentes ignoram os diversos significados das frações, como os alunos saberão? Será que estes necessitam conhecer todos os conceitos relacionados às frações?

Nunes e Bryant (1997) criticam os professores que privilegiam o significado de parte-todo no trabalho com frações, alegando que esse modo de apresentar o tema às crianças pode, na realidade, conduzi-las ao erro. Para os autores, focar somente nesse significado prejudica a compreensão de que o conjunto dos números racionais é uma extensão do dos números naturais. Em efeito,

\begin{abstract}
Uma forma comum de apresentar as crianças às frações é mostrar lhes todos divididos em partes, alguns dos quais distinguidos do resto, por exemplo, pintados. As crianças são informadas que o número total de partes é o denominador, então, o número de partes pintadas é o numerador. Esta introdução, junto com alguma instrução sobre algumas regras para calcular, permite que as crianças transmitam a impressão de que sabem muito sobre fração. (NUNES; BRYANT, 1997, p. 191)
\end{abstract}

Na mesma linha argumentativa, Lamon (2007) enfatiza que se faz necessário o ensino dos diferentes significados de frações para que o aluno compreenda o conjunto de números racionais. $\mathrm{O}$ autor destaca que, tradicionalmente, os discentes são confrontados apenas com a definição de fração como parte-todo, o que os deixa com uma noção 
empobrecida de número racional. Segundo ele, é mister que os próprios docentes conheçam (ou desenvolvam na sua formação) esses conceitos, bem como as diversas formas de explorá-los e abordá-los em sala de aula.

Em relação ao percentual de participantes - 20\% - que não respondeu ou afirmou desconhecer o conceito de frações, constatou-se que eram professores que ministravam aula nos Anos Iniciais do Ensino Fundamental. Acredita-se que esses profissionais possuidores de limitações conceituais em relação aos números racionais se deparavam com obstáculos ao trabalharem com os diversos registros desse conteúdo, especialmente com os diferentes significados.

Justulin e Pirola (2008) também constataram que docentes dos Anos Iniciais apresentavam dificuldades em relação às frações e a forma de ensiná-las, podendo levar a uma aprendizagem fragmentada ou pautada em aspectos mecânicos. Os nomeados autores enfatizam a importância da formação dos professores desse nível de escolaridade que possuíam uma formação não específica da Matemática, sendo os responsáveis pela formação inicial do aluno. Diante disso, questiona-se: como esses profissionais poderão estimular nos estudantes o desenvolvimento de significado desse conteúdo, desconhecendo, eles próprios, tais situações?

Assim, concorda-se com A. Silva (2009, p. 14) quando comentam haver a "necessidade de rediscutir as formas como os conteúdos matemáticos e, em especial, os números racionais são introduzidos - quando o são - nos cursos de formação, tanto inicial quanto continuada." Os referidos autores apontam que as dificuldades dos docentes relativas ao conhecimento matemático influenciam na prática e indicam a necessidade de que haja "um enfoque mais amplo do conceito de números racionais, complementado por uma análise dos diferentes significados da representação fracionária dos números racionais tanto no curso de formação inicial quanto no de formação continuada." (SILVA, A. 2009, p. 14).

Valera (2003, p. 150) também apresenta uma reflexão quanto ao trabalho do professor: "Não seria aconselhável usar uma metodologia para o ensino das frações que ampliasse os exemplos e contextos para além dos velhos recursos de cortar pizzas e partir barras de chocolate?" Para o autor, a motivação para o ensino de frações pode ser efetivada por "meio da representação geométrica de conceitos ou fatos aritméticos e 
algébricos e, especialmente, de operações e problemas envolvendo grandezas contínuas." (SILVA, A. 2009, p. 14).

b) Qual a importância das frações no currículo?

No quadro 2 são apresentadas as respostas identificadas para esta pergunta com o respectivo percentual de respondentes.

Quadro 2 - Resposta à pergunta “Qual a importância das frações no currículo?”

\begin{tabular}{|l|c|}
\hline \multicolumn{1}{|c|}{ Respostas identificadas } & Percentual (\%) \\
\hline A importância é para a vida & 31 \\
\hline Para dividir um todo & 25 \\
\hline Para entender melhor as divisões & 23 \\
\hline Para desenvolver o raciocínio & 04 \\
\hline Para noções de medida & 04 \\
\hline Serve como base para outros conteúdos & 03 \\
\hline Não responderam & 10 \\
\hline
\end{tabular}

Fonte: Produção dos autores, 2018.

Observa-se, no Quadro 2, que a maioria das respostas demonstram o não entendimento da questão, já que estão relacionadas às aplicações do ensino de frações no cotidiano e não à importância no currículo escolar. Entretanto, deduz-se que as afirmações "para entender melhor as divisões"; "serve de base para outros conteúdos"; “para noções de medida”, talvez, tenham relação com a questão do currículo escolar. Tais respostas demonstram "a crença no caráter categórico e acumulativo dos conteúdos, bastando ensinar frações em algum ponto do programa." (LOPES, 2008, p. 10). Assim, ficam alguns questionamentos: os professores investigados sabiam o porquê de ensinar frações? Por que ensinavam conceitos relacionados com os números fracionários em determinado nível de escolaridade? Por que aparecem as frações no currículo escolar?

Aliado a essa questão, sabe-se que o ensino das frações é usualmente ensinado no $6^{\circ}$ ano (antiga $5^{\text {a }}$ série) do Ensino Fundamental com mais intensidade. Assim sendo, por que esse conteúdo é enfatizado nesse nível de escolaridade? É possível que os alunos possuam maturidade para aprender alguns assuntos complexos relacionados às frações, tais como entender o que acontece nas operações de multiplicação e divisão? Para Valera (2003, p. 149), “é um grande equívoco pensar o ensino da matemática linearmente, como 
se entre os conteúdos dos números racionais fossem pré-requisito um dos outros, conforme se viu tão questionado no campo da didática". O mencionado autor sustenta a necessidade do ensino de frações em todos os anos de escolaridade da Educação Básica (desde o Ensino Fundamental até o Médio), pois, dessa maneira, oportuniza ao estudante diferentes experiências relacionadas às frações, sendo que a complexidade deveria ir aumentando conforme o avanço de sua escolaridade.

De acordo com Valera (2003), um dos argumentos que justificam a inclusão dos números fracionários no currículo escolar é a necessidade de suprir a impossibilidade da escrita numérica, que há, por exemplo, entre dois números inteiros. Para o autor, "o conjunto dos números racionais torna-se mais denso que o conjunto dos números inteiros, porque supre a insuficiência da representação e quantificação simbólica de quantidades expressas diferentemente do inteiro." (VALERA, 2003, p. 57). Nesse sentido, o autor cita os problemas que envolvem a medida de uma grandeza ou o resultado de uma divisão. Outro argumento por ele citado é que as frações auxiliam a

promover o desenvolvimento e a expansão das estruturas mentais necessárias para o desenvolvimento intelectual. Elas constituem-se como uma base, sobre a qual as operações algébricas serão trabalhadas, em estudos posteriores e, certamente, servirão como auxiliar em outras disciplinas. (VALERA, 2003, p. 59)

Pires (2012) corrobora a opinião de Valera afirmando que, embora a representação decimal esteja mais presente em situações reais, a compreensão das representações fracionárias é importante pela potencialidade no campo da própria Matemática.

c) Cite situações do cotidiano em que usamos frações.

Nessa questão, os professores participantes mencionaram várias situações. Entretanto, a maioria citou receitas, divisão de alimentos (citando pizza, bolo e chocolate) e horas. Em menor número, apareceram medidas, dosagem de remédio, porcentagem, compra de supermercado, proporção. Quanto às frações que usavam nas referidas situações, indicaram meios, terços, quartos e oitavos. Então, novamente, foram questionados sobre o porquê de ensinar frações com vários denominadores se estas não 
eram usadas. Além disso, fica a pergunta: quanto tempo é dedicado ao ensino de frações do tipo dezesseis trinta e cinco avos (ou tantas outras) e que não têm uso diário?

Para Nascimento (2009, p. 163), vivenciam-se "muito pouco, situações em que são utilizados os números fracionários o uso de frações limita-se a metades, terços, quartos e mais pela via da linguagem oral do que das representações." Nessa mesma linha argumentativa, M. Silva (1997, p. 46) reiterava que o ensino de frações para alunos de oito e nove anos deveria ser repensado, pois eles "não têm contato com números fracionários no seu dia a dia, a não ser com metade, terço ou quarto apenas na linguagem oral, pois não têm necessidade de representar de outra forma esses termos." O autor acrescenta que "o mesmo não acontece com os números decimais que são encontrados com muito mais frequência nas calculadoras, nos preços." (SILVA, M. 1997, p. 47).

Lopes (2008) adota o mesmo raciocínio ao argumentar que o uso dos números da forma fracionária, tende a se tornar cada vez mais raro, pois estes se apresentam, geralmente, na forma de número decimal.

Representações analógicas cedem lugar às digitais. Já não se encontram com facilidade balanças e instrumentos de medida com ponteiros, como é o caso dos hidrômetros antigos. O visor do odômetro dos automóveis resiste como um dos últimos mecanismos do gênero onde se lê frações, pelo posicionamento dos ponteiros numa escala, para saber se o tanque tem cerca de $1 / 4,1 / 2$ ou $3 / 4$ de combustível. Temos que reconhecer estes fatos e nos ajustar à realidade. A notação decimal ganhou a guerra da comunicação e da usabilidade para representar números "quebrados", não inteiros. Isto não quer dizer que as frações devam ser abolidas, temos que reconhecer sua importância em contextos não utilitários, que atendem a outros significados e objetivos. (LOPES, 2008, p. 5)

Concorda-se com Lopes (2008) que é preciso repensar os objetivos e os significados que estão sendo dados a esse tipo de número e não abolir tal assunto dos currículos escolares. Ademais, é necessário, de acordo com Lamon (2012), que o professor tenha clareza das dificuldades de ensinar e aprender frações, bem como dos aspectos que podem influenciar a aprendizagem dos alunos em relação a esse tema. Assim, é imprescindível adotar novas práticas, métodos, metodologias e estratégias de ensino ao abordar esse tema na Educação Básica. 
Diante desse contexto, proporcionaram-se, durante os encontros de formação continuada que ocorreram nas próprias escolas parceiras, vários momentos de reflexão e discussão sobre as frações. Os referidos encontros duraram, aproximadamente, três horas cada um, em cada educandário. No primeiro, além da discussão das três questões aqui socializadas, foram exploradas formas de introduzir as frações por meio de simetria; em seguida, utilizaram-se caixas de ovos para o conceito de fração com quantidade discreta. Salientou-se a necessidade de não usar somente retângulos e círculos para representar frações, enfatizando o emprego de formas geométricas regulares e irregulares. No quadro 3, estão algumas figuras utilizadas para representar frações'.

Quadro 3: Exemplos de atividade desenvolvida na formação continuada Pintar em cada figura a fração indicada.

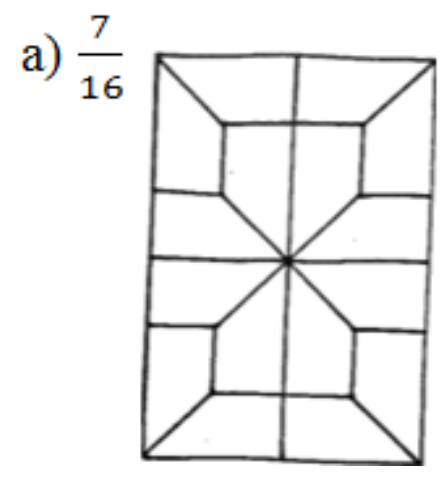

e) $\frac{11}{6}$ b) $\frac{5}{8}$

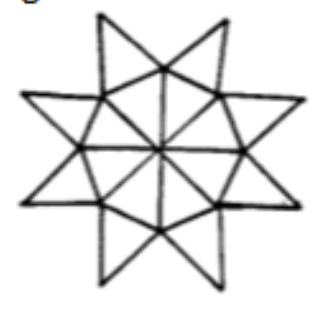

c) $\frac{1}{3}$

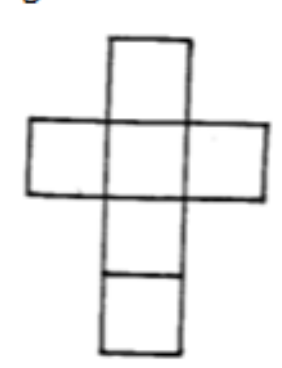

d) $\frac{7}{16}$

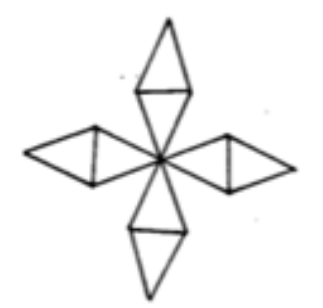

f) $\frac{5}{12}$

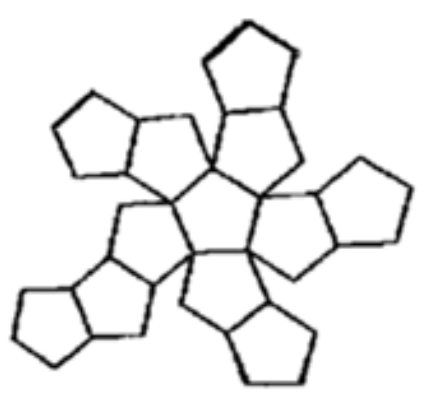

Fonte: adaptado de Rehfeldt, Quartieri, Giongo (2017).

O emprego de figuras diversas para representar frações gerou espanto na maioria dos professores, pois eles nunca haviam pensado em representá-las a não ser com o uso

\footnotetext{
${ }^{1}$ Salienta-se que, por falta de espaço, não estão apresentadas todas as figuras exploradas. As atividades podem ser encontradas em Rehfeldt, Quartieri, Giongo (2017).
} 
de retângulos e círculos. Além disso, explorar, na representação de frações, a equivalência destas também foi motivo de discussões. Os docentes, em particular dos Anos Iniciais, tiveram dificuldades em pintar as que constam nas letras b, d, e. Salienta-se que os obstáculos enfrentados pelos de Matemática ocorreram na letra e. Ao final da correção dessa atividade, os participantes foram unânimes em comentar quanto à necessidade de se (re)pensar e (re)planejar as atividades envolvendo frações.

No segundo encontro, problematizou-se a importância de relacionar as diferentes formas de representar o número racional nas formas de fração, de decimal e de porcentagem. Essas representações, concomitantemente, foram exploradas usando-se o papel quadriculado. Ademais, desenvolveu-se, por meio de cartas, o conceito de probabilidade, que os professores dos Anos Iniciais consideravam muito complexo, sendo, de acordo com eles, também difícil para os seus alunos. Entretanto, de forma unânime, declararam que a representação na forma decimal deveria ser explorada desde esse nível de escolaridade por fazer parte do cotidiano das crianças.

As operações de adição e subtração, foco de estudo do terceiro encontro, foram exploradas por meio do Tangran e de frações equivalentes. Para o ensino de equivalência de frações, utilizou-se papel quadriculado, simetria e dobraduras. A maioria, ou seja, 90\% dos participantes, destacou que só aprendeu essas duas operações usando o mínimo múltiplo comum, motivo pelo qual ensinava dessa forma. A falta de conhecimento de outras maneiras de ensinar as operações com números fracionários, de acordo com Mandarino (2006), pode ser o motivo de os docentes seguirem "receitas prontas", ou seja, ensinarem como aprenderam em seu tempo de estudantes do Ensino Fundamental: por meio da mecanização e memorização de procedimentos sem a devida compreensão dos conceitos envolvidos. Os 10\% restantes, diplomados em Licenciatura em Matemática, comentaram que aprenderam a ideia de frações equivalentes apenas em seu Curso de Graduação.

No quarto encontro, foram discutidas e exploradas as operações de multiplicação e divisão de frações. Para tanto, usaram-se dobraduras e recortes. Cumpre salientar que os participantes custavam a entender essas operações, inclusive os licenciados em Matemática. Estes sabiam resolver o cálculo por meio do algoritmo; porém, tiveram dificuldades para mostrar o que representava cada operação. Ademais, a maioria 
comentou que nunca havia visto essa forma de ensinar as operações com números fracionários, fato que confirma o que Valera (2003, p. 119) encontrou em sua pesquisa, isto é "O tratamento didático usual das frações nas escolas tem sido orientado pela utilização de mecanismos, dispositivos práticos e regras realizadas à base de repetição, sem suas devidas compreensões, enfocando apenas a memorização rotineira." Para o autor, tais orientações são encontradas na maioria dos livros didáticos e, por esse motivo, muito utilizadas pelos docentes que desconhecem outras formas de ensino desse assunto.

Por conseguinte, infere-se o quanto é importante, em cursos de formação de professores, proporcionar momentos de exploração, problematização e reflexão sobre questões conceituais e metodológicas. Nesse sentido, Costa afirma que

é uma proposta de formação continuada em serviço, que não se reduz a uma ação compensatória de fragilidade da formação inicial, mas sim com o propósito de aproveitar os conhecimentos já adquiridos ao longo do tempo pelo ofício do professor. (...) visa propiciar a troca de experiências bem sucedidas em sala de aula, (...) além de buscar desenvolver uma atitude investigativa e reflexiva, tendo em vista que a atividade profissional é o campo de produção do conhecimento, pois envolve aprendizagens que vão além da simples aplicação do que foi estudado. (COSTA, 2010, p. 27-28)

Nessa perspectiva, entende-se que a formação continuada é capaz de propiciar condições para que os conhecimentos construídos durante a formação inicial sejam revistos e reconstruídos no decorrer da vida profissional. Isso se deve às novas demandas que surgem durante o exercício da prática pedagógica. 


\section{Considerações finais}

Para Fiorentini, a experiência de aprendizagem colaborativa pode contribuir significativamente para o desenvolvimento profissional do professor, pois

o trabalho colaborativo, mediado pela reflexão e investigação sobre a própria prática, é uma estratégia poderosa de educação contínua de professores, pois o professor, frente aos desafios diários, busca, continuamente, com o grupo, novos saberes e arrisca-se em novas experiências docentes, re-significando permanentemente sua prática e seus saberes. [...] O professor não apenas acompanha e recebe novos conhecimentos e ideias, mas, também troca e contribui, tornando-se protagonista da cultura profissional de seu campo de trabalho. (FIORENTINI, 2006, p. 34)

Durante os encontros de formação continuada, o intuito foi proporcionar aos participantes momentos de reflexão acerca da própria prática, em particular, o ensino de frações. Para tanto, iniciou-se com questões que conduzissem os docentes a meditarem sobre o ensino dos números fracionários.

As respostas dadas às questões revelaram diversas carências sobre o conhecimento matemático relativo, em particular (mas não exclusivamente) aos significados das frações. Quanto ao conceito de frações, a maioria apenas citou o significado relacionado à parte-todo, demonstrando dificuldades em relação aos significados que elas apresentavam (NUNES; BRYANT, 1997).

Em relação à importância do conteúdo de frações no currículo, grande parte não respondeu, e os demais mencionaram questões pertinentes ao uso de frações no cotidiano. Em vista disso, é possível inferir que os docentes ministravam esse conteúdo porque ele fazia parte da grade curricular, sem questionar a necessidade de ensinar essa forma da escrita do número racional. Cumpre destacar que não se pretende abolir o ensino de tal conceito na Educação Básica concordando com Lopes (2008), mas acreditase na importância de (re)pensar o quanto e o como se ensina esse tema.

Os professores foram enfáticos em comentar que as frações eram muito importantes no cotidiano das pessoas, mas, questionados sobre onde apareciam, só citaram receitas, medidas, tempo e divisão de alimentos. Entretanto, nessas situações, apenas se apresentam frações do tipo meios, terços, quartos, oitavos. Os participantes 
também foram unânimes em afirmar que números escritos na forma decimal são mais

utilizados do que os da forma fracionária. Assim questiona-se: por que é dedicado mais tempo para ensinar conteúdos relacionados ao número racional na forma de representação fracionária do que na forma de representação decimal? Não seria o momento de repensar o currículo em relação a esses dois focos? Não se poderia trabalhar com as duas representações concomitantemente? O que realmente é necessário ensinar sobre os números fracionários nos Anos Iniciais do Ensino Fundamental e de que forma, já que é o momento de adquirir a base para estudos futuros?

\section{Referências}

BARDIN, Laurence. Análise de conteúdo. Trad. Luís Antero Reto. São Paulo: Edições 70, 2016.

BEHR, Merlyn; LESH, Richard; POST, Thomas; SILVER, Edward. Rational number concepts. In: LESH, Richard; LANDAU, M. (ed.). Acquisition of mathematics concepts and processes. New York: Academic Press, 1983.

CAMPOS, Tânia Maria. Considerações a respeito do ensino e aprendizagem de representações fracionárias dos números racionais. In: GUIMARÃES, Gilda; BORBA, Rute. (eds.), Reflexões sobre o ensino de matemática nos anos iniciais da escolarização. Recife: SBEM, 2009. p. 131-139).

CANOVA, Raquel Factore. Crença, concepção e competência dos professores do $1^{\circ}$ e $2^{\circ}$ ciclos do ensino fundamental com relação à fração. 2006. Dissertação (Mestrado em Educação) - Pontifícia Universidade Católica, São Paulo. 2006.

COSTA, Michel da. Resolução de problemas na formação continuada do professor dos anos iniciais do ensino fundamental: contribuições do pró-letramento no município de Cubatão. 2010. Dissertação (Mestrado em Educação Matemática) - Universidade Bandeirante de São Paulo, São Paulo, 2010.

FIORENTINI, Dario. Grupo de Sábado: uma história de reflexão, investigação e escrita sobre a própria prática escolar em matemática. In: CRISTOVÃO, Eliane Matesco, FIORENTINI, Dario. (org). Histórias e investigações de/em aulas de matemática. Campinas, SP: Editora Alínea, 2006.

FLICK, Uwe. Introdução à metodologia de pesquisa: um guia para iniciantes. Trad. Magda Lopes. Porto Alegre: Penso, 2013. 
IMBERNÓN, Francisco. Formação continuada de professores. Porto Alegre: Artmed, 2010. $120 \mathrm{p}$.

JUSTULIN, Andresa Maria; PIROLA, Nelson Antonio. Um estudo sobre as relações entre as atitudes em relação à matemática e a resolução de problemas envolvendo frações. [S.l.: s.n.], 2008. Disponível em: http://www2.rc.unesp.br/eventos/matematica/ebrapem2008/ upload/304-1-A-gt3_Justulin_ta.pdf. Acesso em: 05 fev. 2018.

LAMON, Susan. Rational numbers and proportional reasoning. In: LESTER, Frank. (ed.), Second handbook ok mathematics teaching and learning. Greenwich, CT: Information Age Publishing, 2007. p. 629-667.

LAMON, Susan. Teaching fractions and ratios for understanding. In: ESSENTIAL CONTENT KNOWLEDGE AND INSTRUCTIONAL STRATEGIES FOR TEACHERS. 3 th ed. New York: Routledge, 2012.

LOPES, Antônio José. O que nossos alunos podem estar deixando de aprender sobre frações, quando tentamos lhes ensinar frações. Bolema, Rio Claro, SP, Ano 21, n. 31, p. 122, 2008.

MAGINA, Sandra; CAMPOS, Tânia. A fração na perspectiva do professor e do aluno das séries iniciais da escolarização brasileira. Boletim de Educação Matemática, São Paulo, v. 21, n. 31, p. 23-40, 2008.

MANDARINO, Mônica Cerbella Freire. Concepções do ensino da matemática elementar que emergem da prática docente. 2006. Tese (Doutorado em Educação) - Pontifícia Universidade Católica do Rio de Janeiro, Rio de Janeiro, 2006.

MOREIRA, Plínio Cavalcanti; DAVID, Maria Manuela Martins Soares A formação matemática do professor: licenciatura e prática docente escolar. Belo Horizonte: Autêntica, 2007.

NASCIMENTO, Juliane do. O ensino e a aprendizagem das frações no contexto das novas propostas curriculares. Revista de Iniciação Científica da FFC, Marília, v. 9, n. 2, p. 158 -170, 2009.

NUNES, Teresinha; BRYANT, Peter. Crianças fazendo Matemática. Porto Alegre: Artes Médicas, 1997.

PIRES, Célia Maria Carolino. Educação Matemática: conversas com professores dos anos iniciais. São Paulo: Zé-Zapt Editora, 2012.

RANGEL, Letícia; GIRALDO, Victor; MACULAN FILHO, Nelson. Conhecimento de matemática para o ensino: um estudo colaborativo sobre números racionais. Jornal Internacional de Estudos em Educação Matemática, São Paulo, v. 8, n.2, p. 42-70, 2014. 
REHFELDT, Márcia Jussara; QUARTIERI, Marli Teresinha; GIONGO, leda Maria. Atividades desenvolvidas no observatório da educação: geometria, frações e álgebra. In: GIONGO, leda Maria; MUNHOZ, Angélica (orgs). Observatório da educação IV: currículos e práticas pedagógicas. Porto Alegre: Ed. Criação Humana: Evangraf, 2017. p. 178-221.

RIBEIRO, Alessandro Jacques. Equação e conhecimento matemático para o ensino: relações e potencialidades para a Educação Matemática. Bolema, Rio Claro, SP, v. 26, p. 535-558, 2012.

SILVA, Maria José Ferreira da. Sobre a introdução do conceito de número fracionário. 245p. 1997. Dissertação (Mestrado em Ensino da Matemática) -Pontifícia Universidade Católica de São Paulo, São Paulo, 1997.

SILVA, Angélica da Fontoura Garcia. 0 desafio do desenvolvimento profissional docente: análise da formação continuada de um grupo de professores das séries iniciais do ensino fundamental, tendo como objeto de discussão o processo de ensino e aprendizagem das frações. 2007. Tese (Doutorado em Educação Matemática) - Pontifícia Universidade Católica de São Paulo, São Paulo, 2007.

SILVA, Angélica da Fontoura Garcia. Conhecimento profissional docente de professores dos anos iniciais em um processo de formação continuada, tendo como objeto de discussão o processo de ensino e a aprendizagem das frações. In: SEMINÁRIO INTERNACIONAL DE PESQUISA EM EDUCAÇÃO MATEMÁTICA - SIPEM, 4., Taguatinga. Anais [...]. Taguatinga, DF: SIPEM, 2009.

VALERA, Alcir Rojas. Uso social e escolar dos números racionais: representação fracionária e decimal. 164p. 2003. Dissertação (Mestrado em Educação) - Faculdade de Filosofia e Ciências, Marília, 2003.

TARDIF, Maurice. Saberes docentes e formação profissional. Petrópolis, RJ: Vozes, 2002.

Recebido em: 24/03/2018 Revisões requeridas: 10/05/2018 Aprovado em: 27/09/2018

Universidade do Estado de Santa Catarina - UDESC Programa de Pós-Graduação em Educação - PPGE

Revista Linhas

Volume 21 - Número 45 - Ano 2020 revistalinhas@gmail.com 